\title{
Apoptosis and proliferation in the trigeminal placode
}

\author{
Wolfgang Knabe $\cdot$ Bastian Obermayer • \\ Hans-Jürg Kuhn • Guido Brunnett • \\ Stefan Washausen
}

Received: 26 September 2009/ Accepted: 27 October 2009/Published online: 14 November 2009

(C) The Author(s) 2009. This article is published with open access at Springerlink.com

\begin{abstract}
The neurogenic trigeminal placode develops from the crescent-shaped panplacodal primordium which delineates the neural plate anteriorly. We show that, in Tupaia belangeri, the trigeminal placode is represented by a field of focal ectodermal thickenings which over time changes positions from as far rostral as the level of the forebrain to as far caudal as opposite rhombomere 3. Delamination proceeds rostrocaudally from the ectoderm adjacent to the rostral midbrain, and contributes neurons to the trigeminal ganglion as well as to the ciliary ganglion/ oculomotor complex. Proliferative events are centered on the field prior to the peak of delamination. They are preceded, paralleled and, finally, outnumbered by apoptotic events which proceed rostrocaudally from non-delaminating to delaminating parts of the field. Apoptosis persists upon regression of the placode, thereby exhibiting a massive "wedge" of apoptotic cells which includes the postulated position of the "ventrolateral postoptic placode" (Lee et al. in Dev Biol 263:176-190, 2003), merges with groups of lens-associated apoptotic cells, and disappears upon lens detachment. In conjunction with earlier work
\end{abstract}

W. Knabe and B. Obermayer contributed equally to this work.

W. Knabe $(\bowtie) \cdot$ B. Obermayer · H.-J. Kuhn Department of Anatomy and Embryology,

Georg August University, Kreuzbergring 36, 37075 Göttingen, Germany

e-mail: wknabe@gwdg.de

G. Brunnett

Department of Informatics,

Technical University, 09107 Chemnitz, Germany

S. Washausen

C. and O. Vogt Institute of Brain Research,

Heinrich Heine University, 40225 Düsseldorf, Germany
(Washausen et al. in Dev Biol 278:86-102, 2005) our findings suggest that apoptosis contributes repeatedly to the disintegration of the panplacodal primordium, to the elimination of subsets of premigratory placodal neuroblasts, and to the regression of placodes.

Keywords Apoptosis - Proliferation .

Trigeminal placode Rhombomeres - Development .

Mammal

\section{Introduction}

Placodes are transient patch-like thickenings of the head surface ectoderm which subserve functions as diverse as neurogenesis or providing the lens of the dioptric apparatus (Baker and Bronner-Fraser 2001; Schlosser 2006; Webb and Noden 1993). Irrespective of their various properties, all placodes originate from the crescent-shaped panplacodal primordium which delineates the anterior border of the neural plate (Litsiou et al. 2005; McLarren et al. 2003; Schlosser and Ahrens 2004; Streit 2002; for reviews, see Baker and Bronner-Fraser 2001; Brugmann and Moody 2005; Schlosser 2006; Streit 2007). Two processes have been suggested to contribute to the formation of isolated placodes from the contiguous panplacodal primordium: (1) mixed subpopulations of precursor cells of the primordium exhibit extensive migratory movements (Bhattacharyya et al. 2004; Dutta et al. 2005; Streit 2002; Xu et al. 2008) and, secondarily, aggregate in the positions of the definitive placodes under the influence of local inductor molecules (Bailey et al. 2006; Lassiter et al. 2007; Martin and Groves 2006; McCabe and Bronner-Fraser 2008; Nechiporuk et al. 2007). (2) In the tree shrew T. belangeri, a rostrocaudal wave of apoptosis helps to individualize the otic placode 
and the three neurogenic epibranchial placodes which, in the beginning, share a primordial low grade thickening. In their rostrocaudal order of appearance, these placodes are demarcated from each other by band-like formations of apoptotic cells (Washausen et al. 2005). However, contributions of apoptosis to placode morphogenesis go beyond the period of placode individualization. In all mature epibranchial placodes, spatiotemporally regulated apoptosis eliminates subpopulations of premigratory neuroblasts throughout the delamination period. Finally, apoptosis drives the regression of the epibranchial placodes. Of note, the rostrocaudally propagating wave of apoptosis is preceded and, partly, overlapped by a rostrocaudal wave of proliferative events (Washausen et al. 2005).

The present study aims to clarify whether, in $T$. belangeri, spatiotemporally regulated waves of proliferation and apoptosis also contribute to the development of the neurogenic trigeminal placode. Analyses were carried out using three-dimensional reconstruction techniques which are particularly suitable to visualize complex patterns of cellular events in large objects (Brunnett et al. 2003; Kienel et al. 2007; Knabe et al. 2002, 2004; Süss et al. 2002; Washausen et al. 2005). Our multiparametric threedimensional reconstructions revealed positional changes of a field of focal ectodermal thickenings (referred to below as the placodal field) which, in the beginning, resided adjacent to the forebrain and midbrain, and, ultimately, gave rise to the trigeminal placode. Obviously, rostralmost parts of the early developing placodal field went beyond the boundaries of the trigeminal placode recently determined in chick embryos (Xu et al. 2008). It will be discussed whether these rostralmost parts of the placodal field belong to the ophthalmic trigeminal placode (McCabe et al. 2009) and/or whether they embody structural equivalents of a "ventrolateral postoptic placode". In chick embryos, this novel placode "is likely to be a ventral extension of the rostral trigeminal ophthalmic placode", and provides sensory neurons for the ciliary ganglion and its associated structures (Lee et al. 2003). In T. belangeri, spatiotemporally regulated patterns of apoptosis and proliferation were found in non-delaminating rostralmost parts of the placodal field, in the postulated position of the ventrolateral postoptic placode, and in the mature trigeminal placode. These patterns included minute numbers of apoptotic events which, due to the "diffuse" structure of the placodal field, very likely would have escaped notice without performing three-dimensional reconstructions. In conjunction with earlier findings in the developing epibranchial placodes (Washausen et al. 2005), the present results raise the possibility that spatiotemporally regulated waves of apoptosis and proliferation play a general role during placode morphogenesis, including contributions to the transformation of the panplacodal primordium into isolated placodes.

\section{Materials and methods}

Animals

Pregnant Tupaia belangeri (Tupaiidae, Scandentia, Archonta, Eutheria, see Asher et al. 2009) were obtained from the former breeding colony of the Battelle-Institute, Frankfurt/ Main (Dr. Anita Schwaier), and from the colony of the German Primate Center (DPZ), Göttingen, for unrelated projects of the former Sonderforschungsbereich 89 (Cardiology). The average gestation period of $T$. belangeri is 43.7 days (Kuhn and Schwaier 1973). The husbandry of the colony was approved by the veterinary authorities (Az: $32.22 / \mathrm{Vo}$ and 10-1.031Ri/Lo). Detailed descriptions of $T$. belangeri, of the animals from our collection, and of the preparation procedures used have been provided in previous reports (Knabe and Kuhn 1998; Knabe et al. 2007, 2008). In brief, tree shrews were killed in accordance with German law by intraperitoneal injection of pentobarbitone sodium (Nembutal). Thereafter, the animals were perfused with $0.15 \%$ procaine hydrochloride (Novocain) in dextran solution (Macrodex) and, subsequently, with 4\% glutaraldehyde/ $3 \%$ paraformaldehyde in phosphate buffer $(\mathrm{pH}$ 7.3). Embryos were removed from the uterine cavity, further fixed by immersion in the same fixative, and processed as specified in Table 1. All specimens used to build up three-dimensional reconstructions were embedded in Araldite (Serva, Heidelberg, Germany), and serially sectioned at $1 \mu \mathrm{m}$ ("semithin"). Consecutive sections were alternately placed on two sets of slides. Sections of the "working series" (Knabe et al. 2002) were stained with Heidenhain's hematoxylin (Romeis 1989) for the purpose of diagnosing cellular events. Contours of the embedding block which served as external reference points during the realignment of consecutive histological sections were taken from corresponding unstained sections of the "reference series" (Knabe et al. 2002).

For staging of the embryos, six previously characterized phases of eye development were used (Knabe and Kuhn 1998; Washausen et al. 2005). To provide comparison with mouse development, the corresponding Theiler stage (TS; Theiler 1989) is specified for each phase. The "V-shaped optic evagination" is a characteristic feature of all phase 1 embryos studied. Except for the anterior neuropore, all other parts of the cranial neural tube are closed or at least in the process of fusion (TS13-TS14). Among reconstructed embryos which belong to a given phase, discrete differences regarding the developmental status are indicated as depicted here exemplarily for phase 1: "Early phase 1 embryo" (DPZ 754/5B, 13 pairs of somites, further referred to as "phase 1a"), "advanced phase 1 embryo" (DPZ 754/1A, 15 pairs of somites: "phase 1b"). In phase 2 ("optic vesicle", TS14), the globular optic vesicle is broadly connected to the forebrain. The cranial neural tube 
Table 1 Embryos of Tupaia belangeri used to investigate the trigeminal placode

\begin{tabular}{|c|c|c|c|}
\hline Phase & $\begin{array}{l}\text { Number of } \\
\text { embryo in } \\
\text { the collection }\end{array}$ & Age (days) & $\begin{array}{l}\text { Fixation, embedding, } \\
\text { thickness of } \\
\text { sections, staining }\end{array}$ \\
\hline $1 \mathrm{a}$ & DPZ 754/5B & 13 & $\mathrm{G} / \mathrm{P}, \mathrm{A}, 1 \mu \mathrm{m}, \mathrm{H}$ \\
\hline $1 b$ & DPZ 754/1A & 13 & $\mathrm{G} / \mathrm{P}, \mathrm{A}, 1 \mu \mathrm{m}, \mathrm{H}$ \\
\hline $2 a$ & DPZ 948/1B & 13 & $\mathrm{G} / \mathrm{P}, \mathrm{A}, 1 \mu \mathrm{m}, \mathrm{H}$ \\
\hline $2 b$ & DPZ 948/8A & 13 & $\mathrm{G} / \mathrm{P}, \mathrm{A}, 1 \mu \mathrm{m}, \mathrm{H}$ \\
\hline \multirow[t]{6}{*}{2} & Bat 196/A & 13 & $\mathrm{~B}, \mathrm{~Pa}, 7 \mu \mathrm{m}, \mathrm{HE}$ \\
\hline & Bat 1284/A & 13 & $\mathrm{~B}, \mathrm{~Pa}, 7 \mu \mathrm{m}, \mathrm{HE}$ \\
\hline & Bat $1396 \mathrm{D} / \mathrm{B}$ & 12 & $\mathrm{G} / \mathrm{P}, \mathrm{A}, 2 \mu \mathrm{m}, \mathrm{H}$ \\
\hline & Bat $1396 \mathrm{D} / \mathrm{C}$ & 12 & $\mathrm{G} / \mathrm{P}, \mathrm{A}, 2 \mu \mathrm{m}, \mathrm{H}$ \\
\hline & Bat $1566 / \mathrm{B}$ & 13 & $\mathrm{G} / \mathrm{P}, \mathrm{A}, 1 \mu \mathrm{m}, \mathrm{A} / \mathrm{M}$ \\
\hline & Bat $1566 / \mathrm{C}$ & 13 & $\mathrm{~B}, \mathrm{~Pa}, 7 \mu \mathrm{m}, \mathrm{HE}$ \\
\hline $3 a$ & DPZ 870/9B & 14 & $\mathrm{G} / \mathrm{P}, \mathrm{A}, 1 \mu \mathrm{m}, \mathrm{H}$ \\
\hline $3 b$ & DPZ 623/9B & 15 & $\mathrm{G} / \mathrm{P}, \mathrm{A}, 1 \mu \mathrm{m}, \mathrm{H}$ \\
\hline \multirow[t]{2}{*}{3} & DPZ 870/11A & 14 & $\mathrm{G} / \mathrm{P}, \mathrm{A}, 1 \mu \mathrm{m}, \mathrm{H}$ \\
\hline & DPZ 870/12C & 14 & $\mathrm{G} / \mathrm{P}, \mathrm{A}, 1 \mu \mathrm{m}, \mathrm{H}$ \\
\hline \multirow[t]{7}{*}{4} & DPZ 743/1A & 15 & $\mathrm{G} / \mathrm{P}, \mathrm{A}, 1 \mu \mathrm{m}, \mathrm{H}$ \\
\hline & Bat 198/A & 14 & $\mathrm{~F}, \mathrm{~A}, 2 \mu \mathrm{m}, \mathrm{H}$ \\
\hline & Bat $198 / \mathrm{C}$ & 14 & $\mathrm{~B}, \mathrm{~Pa}, 10 \mu \mathrm{m}, \mathrm{HW} / \mathrm{A}$ \\
\hline & Bat $962 / \mathrm{C}$ & 14 & $\mathrm{G} / \mathrm{P}, \mathrm{A}, 2 \mu \mathrm{m}, \mathrm{A} / \mathrm{M}$ \\
\hline & Bat 962/D & 14 & $\mathrm{G} / \mathrm{P}, \mathrm{Pa}, 7 \mu \mathrm{m}, \mathrm{HE}$ \\
\hline & DPZ 743/4B & 15 & $\mathrm{G} / \mathrm{P}, \mathrm{GMA}, 3 \mu \mathrm{m}, \mathrm{HE}$ \\
\hline & DPZ 1384/A & 15 & $\mathrm{G} / \mathrm{P}, \mathrm{A}, 1 \mu \mathrm{m}, \mathrm{H}$ \\
\hline 5 & DPZ 5061/C & 16 & $\mathrm{G} / \mathrm{P}, \mathrm{A}, 1 \mu \mathrm{m}, \mathrm{H}$ \\
\hline 6 & Bat 1760/A & 17 & $\mathrm{G} / \mathrm{P}, \mathrm{A}, 1 \mu \mathrm{m}, \mathrm{H}$ \\
\hline
\end{tabular}

A Araldite, A/M Azur II/methylene blue, B Bouin's solution, Bat Battelle-Institute, Frankfurt/Main, $D P Z$ German primate center, Göttingen, $E$ eosin, $F$ formaldehyde, $G$ glutaraldehyde, $G M A$ glycolmethacrylate (Kulzer), $H$ hematoxylin (Heidenhain), HW/A hematoxylin (Weigert)/azophloxin, $P$ paraformaldehyde, $P a$ paraffin

Bold embryo number 3D reconstructed embryo

is completely closed. Reconstructed embryos belong to "phase 2a" (DPZ 948/1B, 19 pairs of somites) or to "phase 2b" (DPZ 948/8A, 20 pairs of somites). Phase 3 embryos are characterized by the onset of the invagination of the optic vesicle which is connected to the developing forebrain by a short optic stalk (TS15). Three-dimensionally reconstructed embryos belong to "phase 3a" (DPZ 870/9B, 27 pairs of somites) or to "phase 3b" (DPZ 623/9B, 31 pairs of somites). In phase 4 ("advanced invagination of the optic vesicle", DPZ 743/1A, 32 pairs of somites, TS15), thickening of the retinal layer in the developing optic cup is more advanced compared with phase 3. Phase 5 embryos ("far advanced invagination of the optic vesicle", TS17-TS18) are characterized by a deeply invaginated, double-layered optic cup. The lens vesicle starts to detach from the surface ectoderm. Phase 5 embryos possess 36-40 pairs of somites (DPZ 5061/C: truncated at lumbar segment 3, Bat. 1778: 36, Bat. 166/A: 40, Bat. 166/B: 40). In phase 6 embryos ("onset of optic fissure closure”, Bat. 1760/A, 46 pairs of somites, TS19), the lens vesicle has completely detached.

\section{Three-dimensional reconstruction}

Detailed descriptions of the methods we used to build up three-dimensional reconstructions from histological serial sections have been provided by Brunnett et al. (2003); Kienel et al. (2007); Knabe et al. (2002), and Süss et al. (2002). In brief, stained semithin sections of the "working series" were scanned at intervals of $2 \mu \mathrm{m}$ with the image acquisition system "Huge Image" (Knabe et al. 2002; Süss et al. 2002) using the $100 \times$ objective (numeric aperture 1.3 , image resolution $0.133 \mu \mathrm{m} /$ pixel $=190.289 \mathrm{dpi}$ ). "Huge image" consists of an Axioskop 2 MOT light microscope (Zeiss, Göttingen, Germany), a motorized scanning table (SCAN $65 \times 50$, Märzhäuser, Wetzlar, Germany), an Axiocam HR digital camera (Zeiss), and a PC running the scanning software KS400 3.0 (Zeiss). Scanned images were saved as 8-bit grayscale TIFF (tagged image file format) files and imported to AutoCAD 2000i (Autodesk, München, Germany). As has been reported by Knabe et al. (2002), cellular events and embryonic contours were manually vectorized in AutoCAD with the help of an Intuos A3 graphics tablet (Wacom, Krefeld, Germany). Generally, three-dimensional reconstructions were built up from serial sections chosen at standardized intervals of $8 \mu \mathrm{m}$. As an exception, intervals of $2 \mu \mathrm{m}$ were introduced in order to facilitate threedimensional reconstructions of the structurally "diffuse" trigeminal placode and of neuroblasts which delaminated from the surface ectoderm. Realignment of vectorized serial sections was done as follows. Vectorized anatomical data (taken from stained sections of the working series) were "fused" with vectorized external reference points (taken from the corresponding unstained sections of the reference series) in AutoCAD. The resulting "hybrid sections" were realigned in AutoCAD (for details, see Knabe et al. 2002). In two cases (embryos belonging to phases 5 and 6), unstained reference series were not available. Consequently, realignment was performed by best-fit of the embryonic contours and corrections were made following the suggestions provided by Süss et al. (2002). Finally, meshwires for embryonic surfaces were generated by applying triangulation algorithms modified from Boissonnat (1988) (Brunnett et al. 2003; Kienel et al. 2007).

Diagnosis of cellular events

Semithin sections stained with Heidenhain's hematoxylin (Romeis 1989) provide favorable conditions for the 
structural diagnosis of apoptotic cells, mitotic figures, delaminating placodal cells, and "grades" of vertically sectioned ectodermal thickenings (Washausen et al. 2005). In brief, useful diagnostic criteria for the identification of apoptotic cells include: (1) their scattered appearance among viable cells, (2) sharp annular chromatin condensations at the nuclear margin, (3) fragmentation of the nucleus, (4) sharply delineated apoptotic bodies of 2-6 $\mu \mathrm{m}$ in diameter, and (5) phagocytosis of apoptotic bodies by adjacent viable cells (Goping et al. 1999; Häcker 2000; Knabe and Kuhn 1998; Sanders and Wride 1995). In previous studies, structural diagnosis of apoptotic cells in hematoxylin-stained semithin sections from the embryos used here was confirmed by applying the TUNEL (terminal deoxynucleotidyl transferase-mediated dUTP nick endlabeling) method to consecutive serial sections (Knabe et al. 2004). Diagnostic criteria used to identify mitotic cells and delaminating neuroblasts are specified in Results section. Following, in principle, Washausen et al. (2005), placodes were identified by vectorizing continuously thickened parts of the surface ectoderm rostral to the first pharyngeal cleft. These thickenings were classified and reconstructed according to four grades (grade 1: "at least one row of cubic epithelium", grade 2: "at least one row of cylindrical epithelium", grade 3: "at least two rows of pseudostratified epithelium", grade 4: "at least three rows of epithelial cells").

\section{Photomicrographs and color-coding}

Photomicrographs were acquired with the "Huge image" system (Knabe et al. 2002; Süss et al. 2002). Shading corrections were performed in KS400. Brightness, contrast and sharpness were adjusted in Photo-Paint 14 (Corel, Unterschleißheim, Germany). In 3D reconstructions (Figs. 2, $3,4,5,6$ ), the embryonic brain (gray) is overlaid with the surface ectoderm (transparent gray). Black contours indicate streams of neural crest cells adjacent to rhombomeres 2 and 4 (phases 1-2) and the developing trigeminal and facial nerves (phases 3-5), respectively. These contours also include the anlage of the trigeminal ganglion. Reconstructions of the surface ectoderm further demonstrate the "placodal field" of focal ectodermal thickenings (green), delaminating neuroblasts (blue), grade 4 thickenings (light gray, Figs. 4, 5, 6) as well as mitotic (yellow, Fig. 4) and apoptotic cells (red, Figs. 5, 6). In 3D reconstructions exhibiting the trigeminal ganglion and/or the developing ciliary ganglion/oculomotor complex (Figs. 7c-f, 8c, d), the embryonic brain (gray) and the trigeminal nerve/ganglion (gray) are shown in combination with the surface ectoderm (Fig. 7c, e: transparent gray; Fig. 7d, f: gray), or in combination with the oculomotor nerve (gray, Fig. 8c, d). These reconstructions additionally demonstrate delaminating placodal neuroblasts (blue, Fig. 7c-f), apoptotic cells (red) within the head mesenchyme (Fig. 7c, e) or within the trigeminal ganglion (Fig. 7d, f) and, finally, large neuroblasts of presumed placodal origin (dark blue, Fig. 8c, d) which reside in close proximity to the ophthalmic and oculomotor nerves.

\section{Results}

Morphogenesis of the trigeminal placode

Hematoxylin-stained semithin sections were used to threedimensionally reconstruct the developing, mature, and regressing trigeminal placode. In a first step, continuously thickened parts of the surface ectoderm rostral to the first pharyngeal cleft were classified according to four grades (see Materials and methods). The ensuing reconstructions revealed the solid lens and olfactory placodes, but did not demonstrate the borders of the trigeminal placode in any of the studied embryos. Hence, in a second step, discrete focal thickenings were included in our reconstructions. In the single section, these focal thickenings consisted of one or two rows of ectodermal cells which either were grouped rosette-like, or exhibited divergent and convergent longitudinal axes respectively, or were horizontally stapled upon each other (Fig. 1a-d). To three-dimensionally reconstruct objects in vector-based systems, mating contours from at least two consecutive sections are required. Therefore, focal thickenings were reconstructed at intervals of 2 instead of $8 \mu \mathrm{m}$ (standard interval) to increase the rate of yield. According to $\mathrm{Xu}$ et al. (2008), ophthalmic parts of the chick trigeminal placode ultimately reside opposite the caudal midbrain and rhombomeres 1 and 2, while maxillomandibular parts are found opposite rhombomeres 2 and 3 . Hence, the developing brain as well as the trigeminal ganglion were included in our reconstructions as topographical landmarks. To unequivocally demonstrate the position of the placode, single or spear-like groups of neuroblasts which delaminated from the ectoderm rostral to the first pharyngeal cleft were also reconstructed (Fig. 1e, f). Delaminating cells were vectorized on condition that their nuclei were dislocated at least half way beyond the level of the basal membrane (for a reference, see Nichols 1986).

In the surface ectoderm rostral to the first pharyngeal cleft, focal thickenings as defined above were found during our phases 1-5 (for details, see Materials and methods). In all studied embryos, these focal thickenings were grouped into a contiguous "placodal field". In phase 1a, rostralmost parts of the field resided at the level of the V-shaped optic evagination, while caudalmost parts did not exceed beyond rhombomeres 1 (right side) or 2 (left side) (Fig. 2a, b). In 
phase $1 \mathrm{~b}$, the placodal field did no longer project rostrally beyond the caudal margin of the V-shaped optic evagination but, in the caudal direction, extended to positions opposite rhombomere 2 on left and right sides of the embryonic head (Fig. 2c, d). In phase 1, delamination of neuroblasts was restricted to a few single cells. With rare exceptions, these cells emigrated from the placodal field opposite the midbrain or rhombomeres 1 and 2 (Fig. 2a-d). In the reconstructed phase 2a embryo, rostral parts of the placodal field persisted in a postoptic position, whereas caudal parts extended beyond the border between the rhombomeres 2 and 3 (Fig. 2e, f). Compared with phase 1 , a considerable increase in the number of delaminating cells was noted. On the right side more pronounced than on the left, most delaminating neuroblasts were grouped into three clusters which resided (1) opposite the rostral midbrain, (2) opposite the caudal midbrain and rhombomere 1, and (3) opposite rhombomere 2 (Fig. 2e, f). In phase 2b, caudalmost parts of the placodal field reached their final position opposite rhombomere 3 (Fig. $2 \mathrm{~g}, \mathrm{~h}$ ). Concomitantly, major alignment of the field changed from rostrocaudal (Fig. 2a-f: phases 1, 2a) to dorsoventral (Fig. 2g, h). In those parts of the placodal field which extended from positions opposite the caudal midbrain to rhombomere 3 , either one single large cluster (right side, Fig. 2h) or three smaller clusters of delaminating cells were noted (Fig. 2g). On the left side, one additional cluster resided adjacent to the rostral midbrain (Fig. 2g). In phase 3a, maximum numbers of delaminating neuroblasts were found in the trigeminal placode (level: caudal midbrain to rhombomere 3 ), most pronouncedly in its maxillomandibular parts (Fig. 3a, b). In contrast, delamination was sparse in rostralmost parts of the placodal field which held positions adjacent to the rostral midbrain. In phases $3 b$ and 4 , regression of the trigeminal placode was indicated by a considerable decrease in the number of focal thickenings, most substantially in its ophthalmic parts. Regression of the placodal field was paralleled by the strong decrease in the number of delaminating cells (Fig. 3c-f) compared with phase 3a (Fig. 3a, b). Correspondingly, only remnants of the maxillomandibular trigeminal placode were noted in phase 5 (Fig. 3g, h).

Apoptosis and proliferation in the trigeminal placode

In order to investigate, whether and to what extent proliferative events contribute to the morphogenesis of the trigeminal placode, mitotic cells (prometaphase to telophase) were reconstructed in the surface ectoderm rostral to the first pharyngeal cleft. Already in phase 1a, higher numbers of mitotic cells were found within the confines of the placodal field compared with its vicinity (Fig. 4b). Cell proliferation in the placodal field peaked in phase $2 \mathrm{~b}$ (Fig. 4c, d) and, thus, preceded the peak of neuroblast delamination by about one phase (Fig. 4e, f). From phase 3a onwards, a rather steep decrease in the number of
Fig. 1 Trigeminal placode, hematoxylin-stained semithin sections $(1 \mu \mathrm{m})$, Tupaia belangeri, phase 3 a. a-d Focal thickenings consist of ectodermal cells that are arranged squamously (a), in horizontal staples (b), spur-like (c), or rosette-like (d).

e, f Neuroblasts delaminate individually (arrowhead in e) or in spear-like groups (arrows in e, f). Neuroblasts (asterisks) of the developing trigeminal ganglion reside immediately beneath the placode. Scale bar $=10 \mu \mathrm{m}$

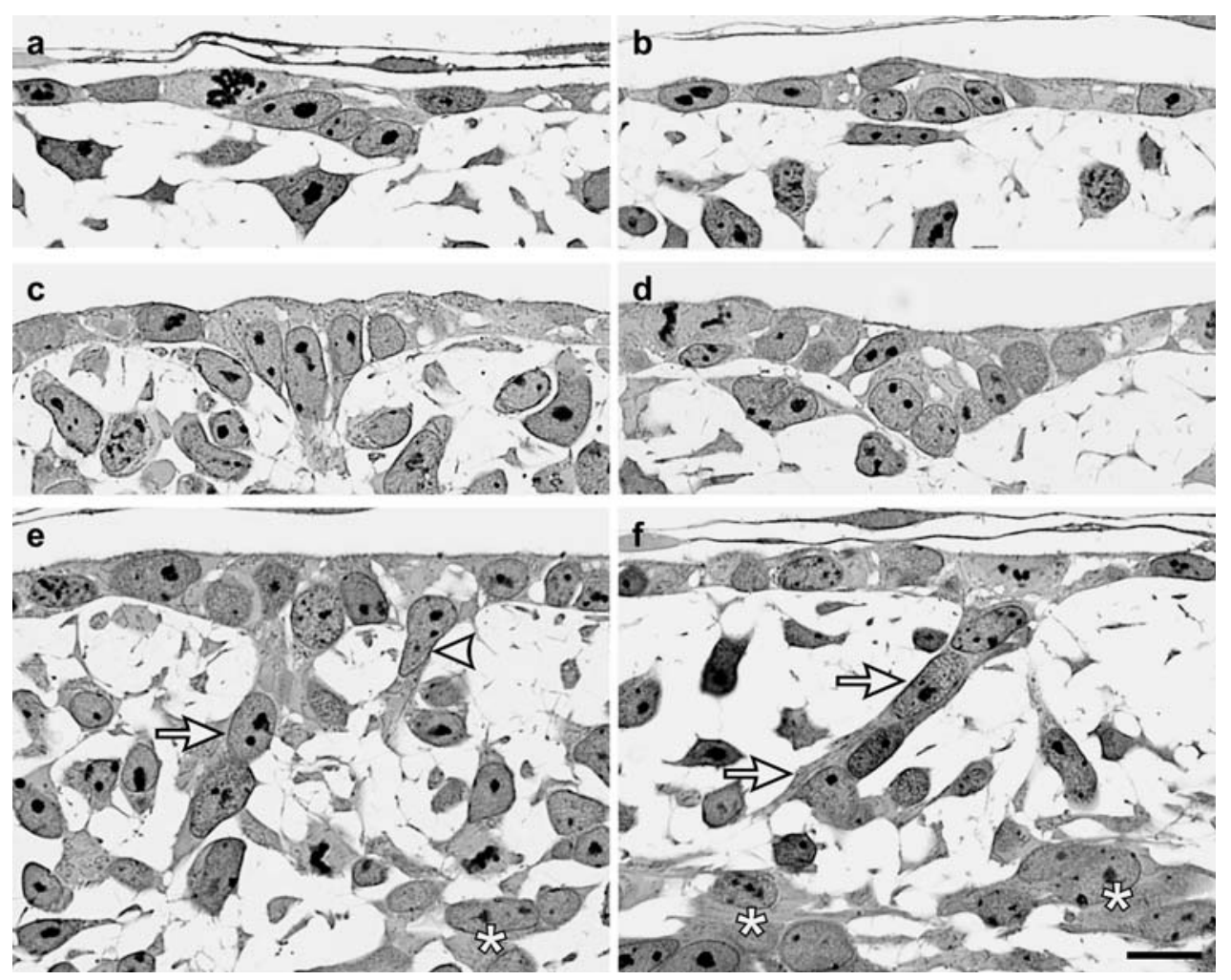


Fig. 2 Onset of trigeminal placode formation, 3D reconstructions, Tupaia belangeri, phases 1 and 2. On left $(\mathbf{a}, \mathbf{c}, \mathbf{e}, \mathbf{g})$ and right sides $(\mathbf{b}, \mathbf{d}, \mathbf{f}, \mathbf{h})$ of the embryonic heads, a "placodal field" of focal thickenings (green) resides in the surface ectoderm (transparent gray) rostral to the first pharyngeal cleft. A comparison with the developing brain (gray) reveals positional changes of the field which extends from the forebrain $(f b)$ to rhombomere $1(1)$ in phase 1 a $(\mathbf{a}, \mathbf{b})$, and from the midbrain $(\mathrm{mb})$ to rhombomere $3(3)$ in phase $2 \mathrm{~b}(\mathbf{g}, \mathbf{h})$. Neuroblasts (blue, 2-fold radius) exclusively delaminate from within the confines of the placodal field. Their number is low in phase 1 (a-d), but high in phase 2 (e-h). At least transiently $(\mathbf{e}-\mathbf{g})$, clusters of delaminating neuroblasts appear to be centered on ophthalmic and maxillomandibular subsections of the trigeminal placode and, possibly, on the postulated position of the ventrolateral postoptic placode (level: rostral midbrain; Lee et al. 2003).

Black lines streams of neural crest cells adjacent to rhombomeres 2 and $4(2,4)$ and the developing trigeminal ganglion, oe optic evagination, ov optic vesicle. Scale bars $=100 \mu \mathrm{m}$
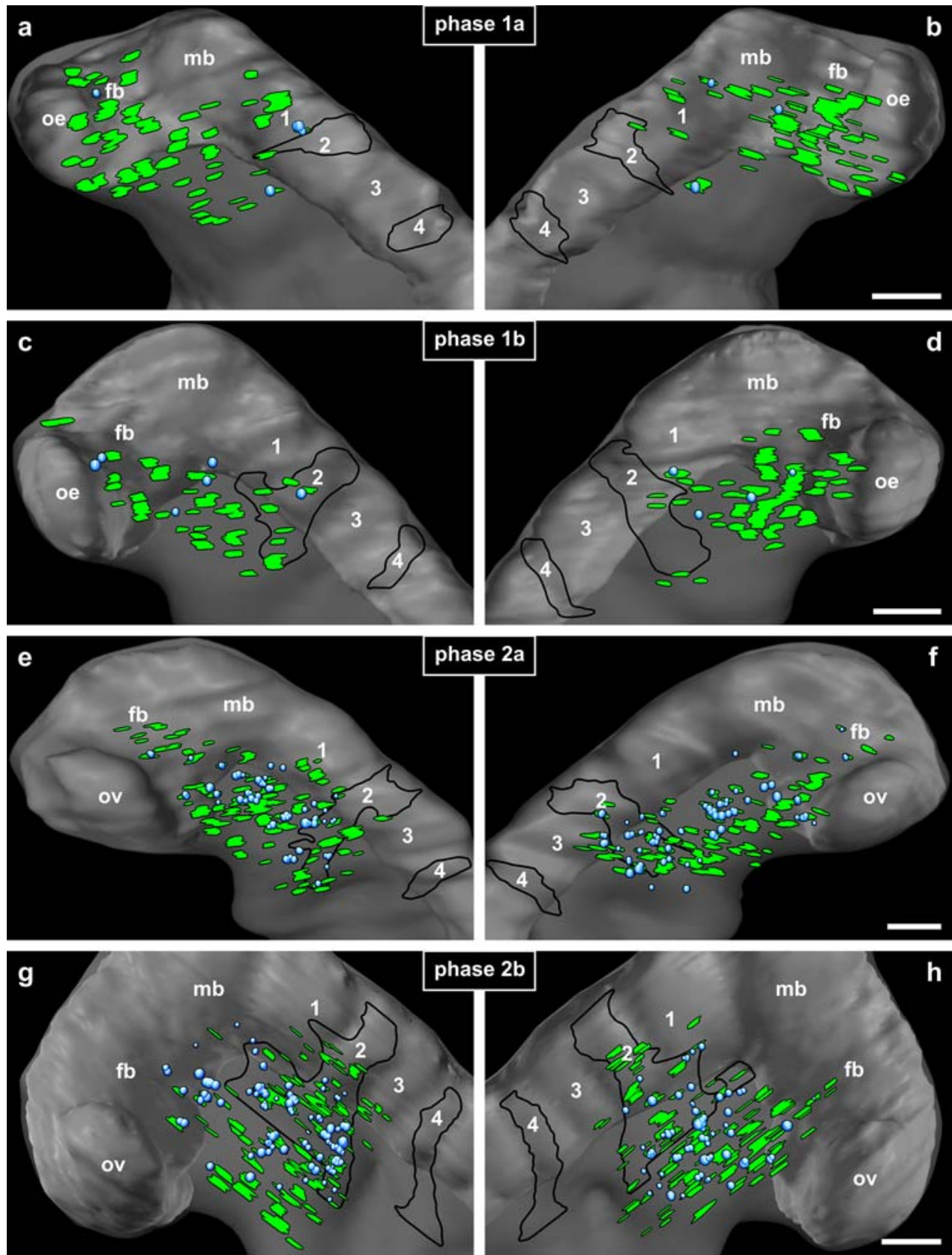

mitotic cells was noted in the placodal field, most pronouncedly adjacent to the caudal midbrain and rhombomeres $1-3$. This decrease was paralleled by an increase of proliferative activity in the developing olfactory and lens placodes (Fig. 4e-h).

We further aimed to clarify whether and to what extent apoptotic events contributed to the morphogenesis of the trigeminal placode. Hence, apoptotic cells were reconstructed in the entire surface ectoderm rostral to the first pharyngeal cleft. In phase 1a, apoptotic cells were concentrated in the dorsal midline of the rostral head ectoderm, including the position of the closing anterior neuropore (Fig. 5a, b). In phase 1b, a band-like formation of apoptotic cells spread caudalward from the dorsal midline and, right but not left side, passed horizontally through the placodal field (Fig. 5c, d). Paralleling the increase in the number of delaminating neuroblasts during phase 2 , moderate concentrations of apoptotic cells persisted in the confines of the placodal field, but remained virtually absent from its immediate vicinity (Fig. 5e-h). In phase 3a, maximum activity of neuroblast delamination in the trigeminal placode coincided with the peak of apoptosis in ophthalmic parts and, less pronouncedly, in maxillomandibular parts of the trigeminal placode (Fig. 6a, b). Densely grouped apoptotic cells in the ophthalmic placode belonged to a "wedge" of apoptotic cells which extended rostrad as far as to the level 
Fig. 3 Mature and regressing trigeminal placode, 3D reconstructions, Tupaia belangeri, phases $3-5$, shown are left $(\mathbf{a}, \mathbf{c}, \mathbf{e}, \mathbf{g})$ and right sides $(\mathbf{b}, \mathbf{d}, \mathbf{f}, \mathbf{h})$ of the embryonic heads. In phase $3 \mathrm{a}$ (a, b), the placodal field of focal ectodermal thickenings (green) is centered on the presumed position of the mature trigeminal placode (level: caudal midbrain $(\mathrm{mb})$ to rhombomere 3, Xu et al. 2008). Shortly thereafter, ophthalmic and, with a delay,

maxillomandibular parts of the placode vanish $(\mathbf{c}-\mathbf{h})$

Delamination of neuroblasts (blue, 2.25- to 4-fold radius) peaks in phase 3a (a, b) and, paralleling the regression of the placodal field, first ceases in ophthalmic parts and, with a delay, in maxillomandibular parts of the placode $(\mathbf{c}-\mathbf{h})$.

Correspondingly, the ophthalmic lobe and nerve (VI) of the trigeminal ganglion (black lines) develop in advance of the maxillomandibular lobe and of the maxillary (V2) and mandibular nerves (V3). 1-4 rhombomeres 1-4, asterisks facial nerve, $f b$ forebrain, gray brain, $o c$ optic cup, ov optic vesicle, transparent gray surface ectoderm. Scale bars $=100 \mu \mathrm{m}$
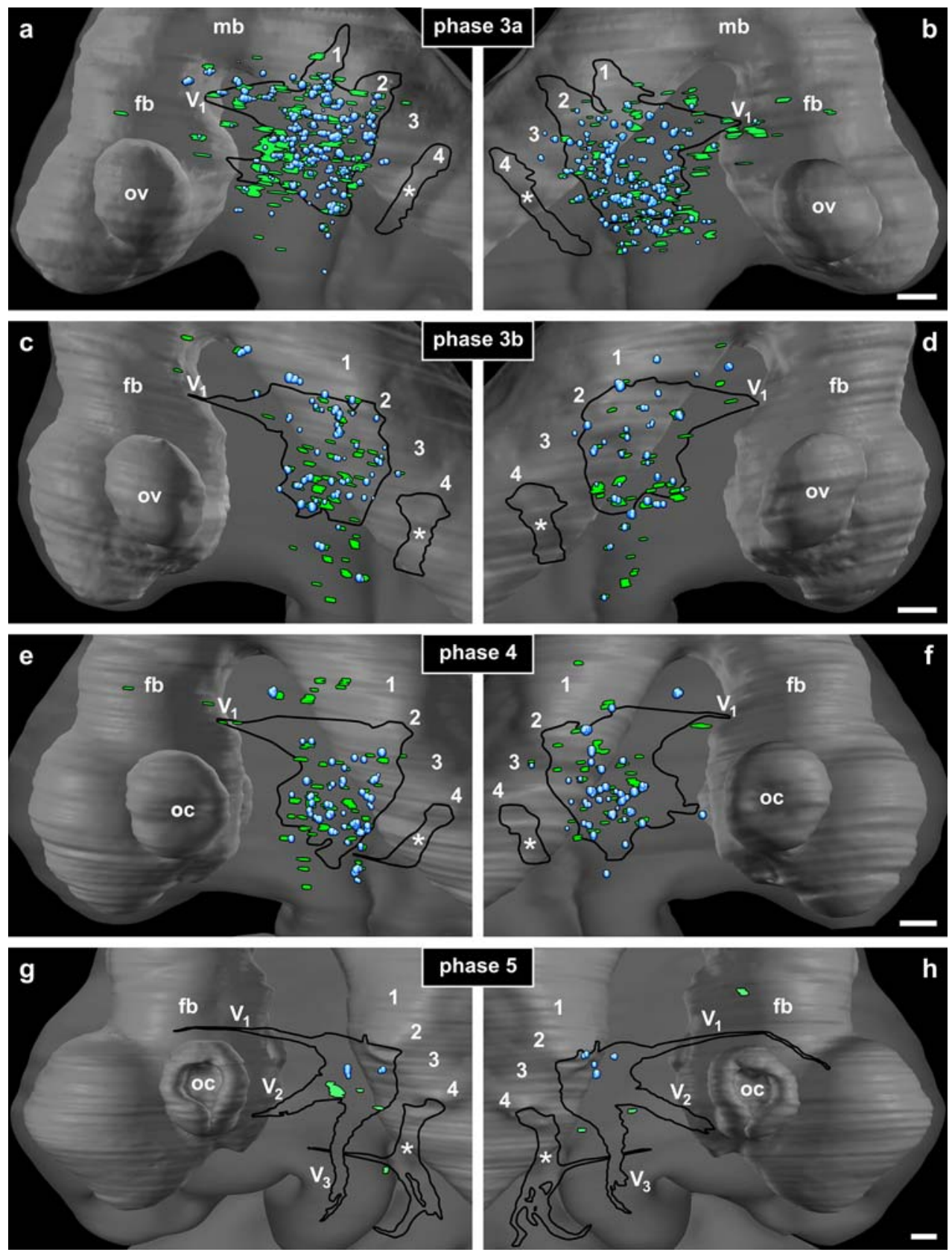

of the caudal forebrain and which, right more than left side, descended ventrad along the rostral border of the maxillomandibular placode (Fig. 6a, b). In phases $3 \mathrm{~b}$ and 4 , moderate numbers of apoptotic cells were found in the regressing maxillomandibular placode (Fig. 6c-f). The pre-existing "wedge" of apoptotic cells persisted and merged with semicircularly arranged groups of apoptotic cells which were associated with the lens placode (Fig. 6c-f). Simultaneously, onset of massive apoptosis in the developing olfactory placode was noted. Upon complete regression of the ophthalmic placode, the wedge of apoptotic cells expanded dorsorostrally beyond the level of the developing ophthalmic nerve (phase 4: Fig. 6e, f). In phase 5, apoptotic cells almost entirely disappeared from the remnants of the trigeminal placode and, except for a few groups of apoptotic cells found dorsally beyond the level of the ophthalmic nerve, from the position of the pre-existing wedge of apoptotic cells. Focal apoptosis persisted at the site of lens detachment as well as in the olfactory placode (Fig. $6 \mathrm{~g}, \mathrm{~h}$, and data not shown).

Complete reconstructions were performed for a total of nine embryos which belonged to phases 1-6 (Table 1). In order to provide a broader basis for the analysis of the developing trigeminal placode, 14 other serially sectioned embryos were studied (phases 2-4, Table 1). Analysis of these additional embryos confirmed that phase 2 embryos 
Fig. 4 Proliferation in the developing, mature, and regressing trigeminal placode, $3 \mathrm{D}$ reconstructions, Tupaia belangeri, phases $1-4$, shown are left $(\mathbf{a}, \mathbf{c}, \mathbf{e}, \mathbf{g})$ and right sides $(\mathbf{b}, \mathbf{d}, \mathbf{f}, \mathbf{h})$ of the embryonic heads. Mitotic cells (yellow, 1.25- to 2.5-fold radius) in the surface ectoderm (transparent gray) rostral to the first pharyngeal cleft are centered on the placodal field of focal thickenings (green) already in phase 1a (a, b) and, much more pronouncedly, in phase $2 b(\mathbf{c}, \mathbf{d})$. During the peak of neuroblast delamination (blue, 2- to 3.25-fold radius), proliferation decreases in the trigeminal placode $(\mathbf{e}, \mathbf{f}$ : phase $3 a)$. This decrease $(\mathbf{e}-\mathbf{h})$ is paralleled by an increase of proliferative activity in the developing lens (triangle) and olfactory placodes (olf) which demonstrate grade 4 thickening (light gray "at least three rows of epithelial cells") from phases 3a (e, f: olfactory placode) or phase 4 (g, h: lens placode) onwards. 1-4 rhombomeres $1-4$, asterisks facial nerve, black lines trigeminal ganglion and nerves, $f b$ forebrain, gray brain, $m b$ midbrain, oe optic evagination, $o v$ optic vesicle, V1 ophthalmic nerve. Scale bars $=100 \mu \mathrm{m}$
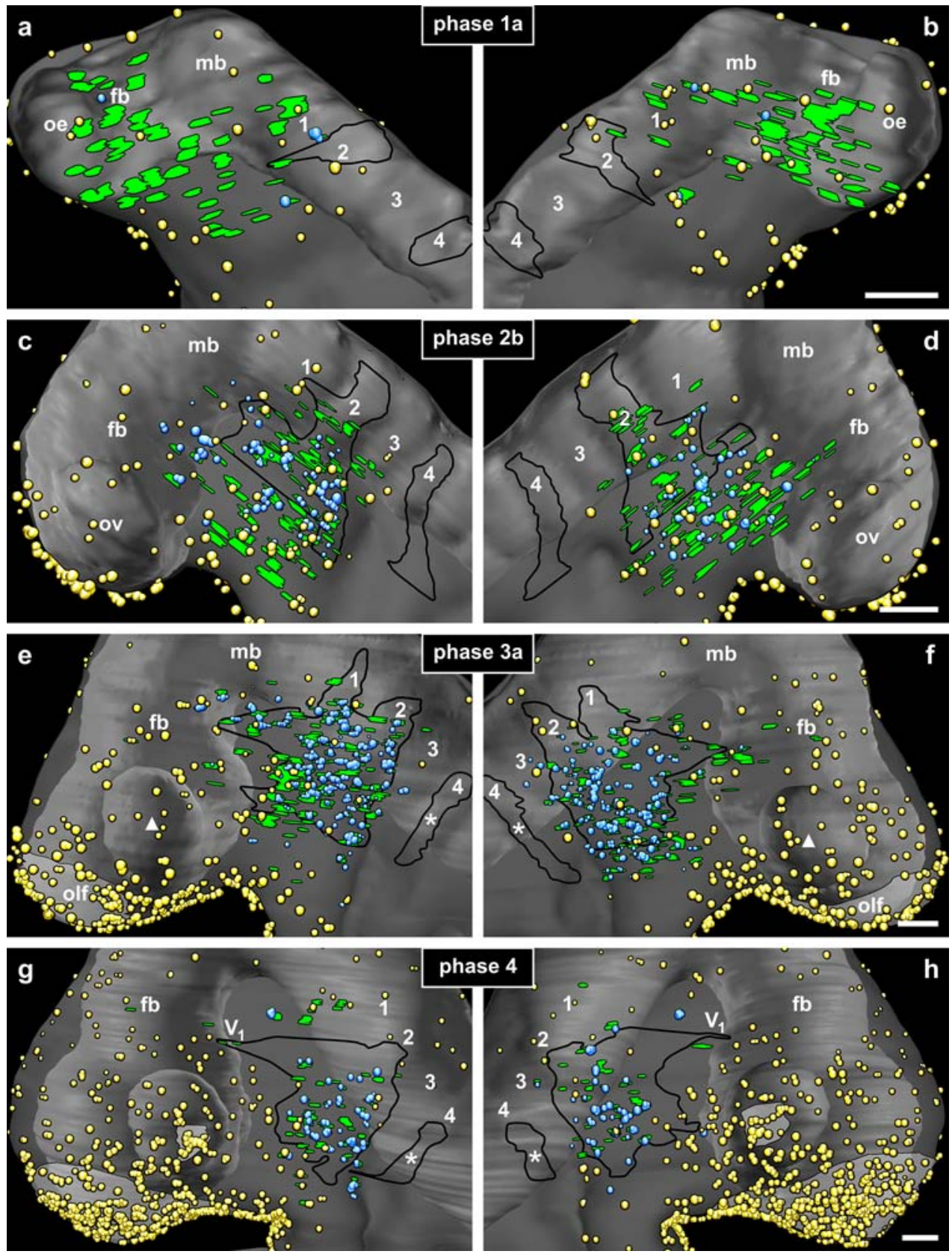

generally were characterized by the presence of a placodal field which extended from positions opposite the caudal forebrain/rostral midbrain to approximately rhombomere 2, and which held moderate numbers of apoptotic cells (Table 2). Embryos belonging to the phases 3 or 4 generally revealed the caudalward shift of the pre-existing placodal field to positions between the midbrain and rhombomere 3. Other constant findings were: (1) the increased numbers of apoptotic cells in the trigeminal placode compared with phase 2 , and (2) the "wedge" of apoptotic cells which resided adjacent to the midbrain and caudal forebrain, and which merged with concentrations of apoptotic cells that were associated with the lens placode.
Morphogenesis of the trigeminal ganglion

Reconstructions of the developing trigeminal ganglion and nerves were made for three reasons: (1) to provide additional topographical landmarks for the identification of the trigeminal placode (Figs. 2, 3), (2) to find out, whether and how patterns of apoptotic events in the trigeminal placode, among migrating neuroblasts, and in the developing trigeminal ganglion were spatiotemporally correlated with each other (Figs. 5, 6, 7), and (3) to facilitate the identification of the ciliary ganglion/oculomotor complex (Fig. 8) which is associated with the ophthalmic nerve and, in chick embryos, receives placodal neuroblasts (Lee et al. 2003). 
Fig. 5 Apoptosis during the onset of trigeminal placode formation, 3D reconstructions, Tupaia belangeri, phases 1 and 2 , shown are left $(\mathbf{a}, \mathbf{c}, \mathbf{e}, \mathbf{g})$ and right sides $(\mathbf{b}, \mathbf{d}, \mathbf{f}, \mathbf{h})$ of the embryonic heads. Apoptotic cells ( red, 2.5- to 3-fold radius) are absent from the placodal field of focal ectodermal thickenings (green) in phase 1a (a, b). In phase $1 \mathrm{~b}$ (c, much more pronouncedly in d), a "band" of apoptotic cells (arrowheads) extends from the dorsorostral midline to positions rostrally ahead of the placodal field and, further, into sparsely delaminating parts of the field. Paralleling the positional changes of the placodal field as well as the initial rise of neuroblast delamination (blue, 2-fold radius), apoptosis remains centered on the field in phase $2(\mathbf{e}-\mathbf{h})$. Note "bands" of apoptotic cells which accompany closure of the anterior neuroporus (stars in a-h). 1-4 rhombomeres 1-4, black lines migrating neural crest cells/anlage of the trigeminal ganglion, $f b$ forebrain, gray brain, $m b$ midbrain, oe optic evagination, $o v$ optic vesicle, transparent gray surface ectoderm. Scale bars $=100 \mu \mathrm{m}$
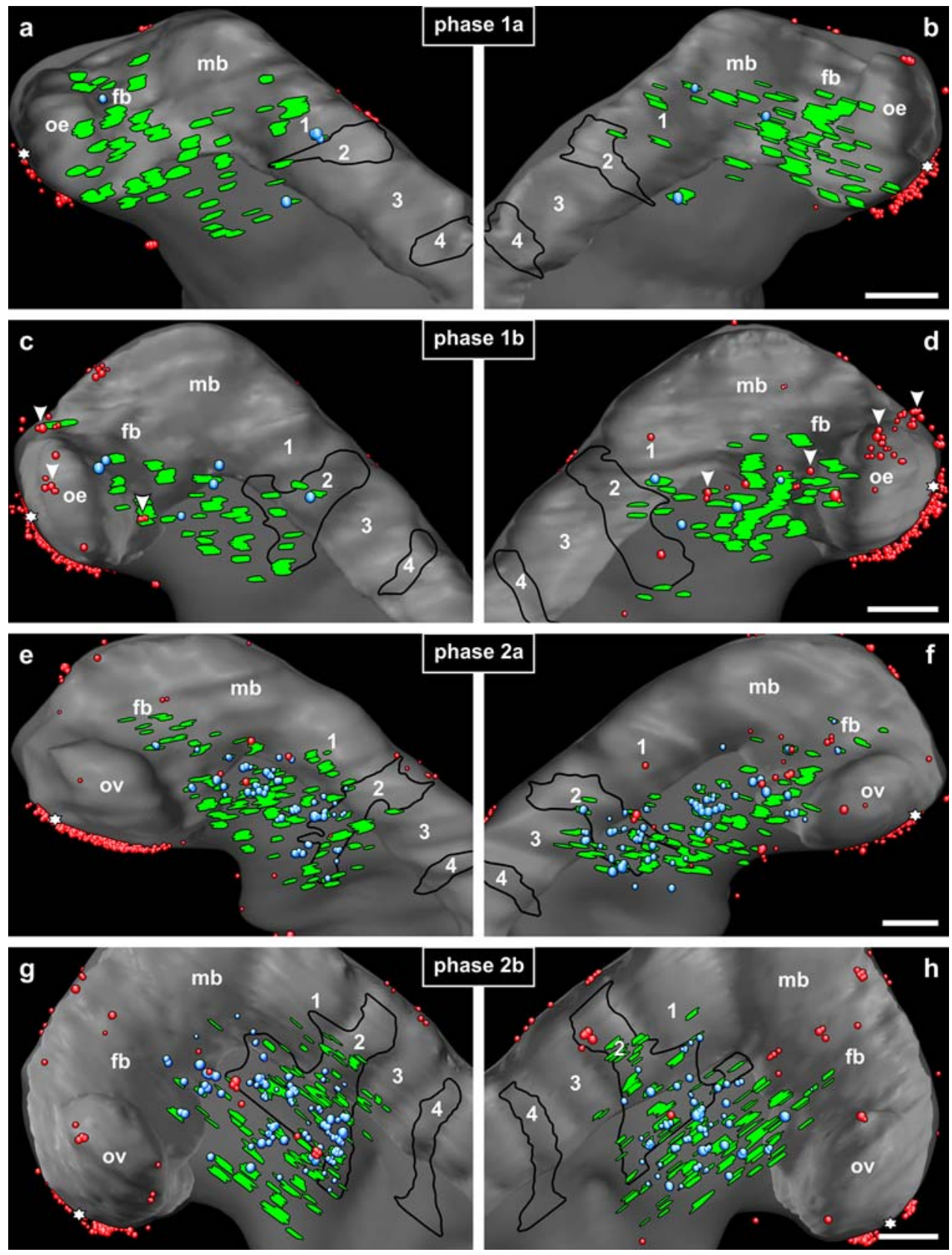

From phase 1 onwards, neural crest cells (rhombomere 2, midbrain) and placodal neuroblasts contributed to the development of the trigeminal ganglion (Figs. 2, 3) which revealed clusters of neurons already in phase 3 (Fig. 1e, f). Outgrowth of the ophthalmic nerve (phase 3 ) preceded that of the maxillary and mandibular nerves by about two phases (Fig. 3). Obviously, subpopulations of neuroblasts delaminated from parts of the placodal field which resided rostrally ahead of the developing trigeminal ganglion as well as of the outgrowing ophthalmic nerve (Figs. 2e-h, 3a, b). During the peak of apoptosis in the trigeminal placode (phase 3a: Fig. 6a, b), high numbers of apoptotic bodies were additionally found within delaminating placodal neuroblasts as well as in the mesenchyme beneath the placode (Fig. 7a, b). In order to analyze apoptotic events inward from the trigeminal placode, apoptotic bodies were reconstructed in the entire mesenchymal compartment of the head and, separately, within the confines of the trigeminal ganglion. In the trigeminal placode, higher numbers of apoptotic cells were found in ophthalmic as opposed to maxillomandibular parts (Fig. 6a, b). Conversely, higher concentrations of apoptotic bodies were observed in the mesenchyme laterally adjacent to the maxillomandibular lobe as opposed to the ophthalmic lobe of the trigeminal ganglion, and much higher numbers of apoptotic bodies resided laterally in the maxillomandibular lobe as opposed 

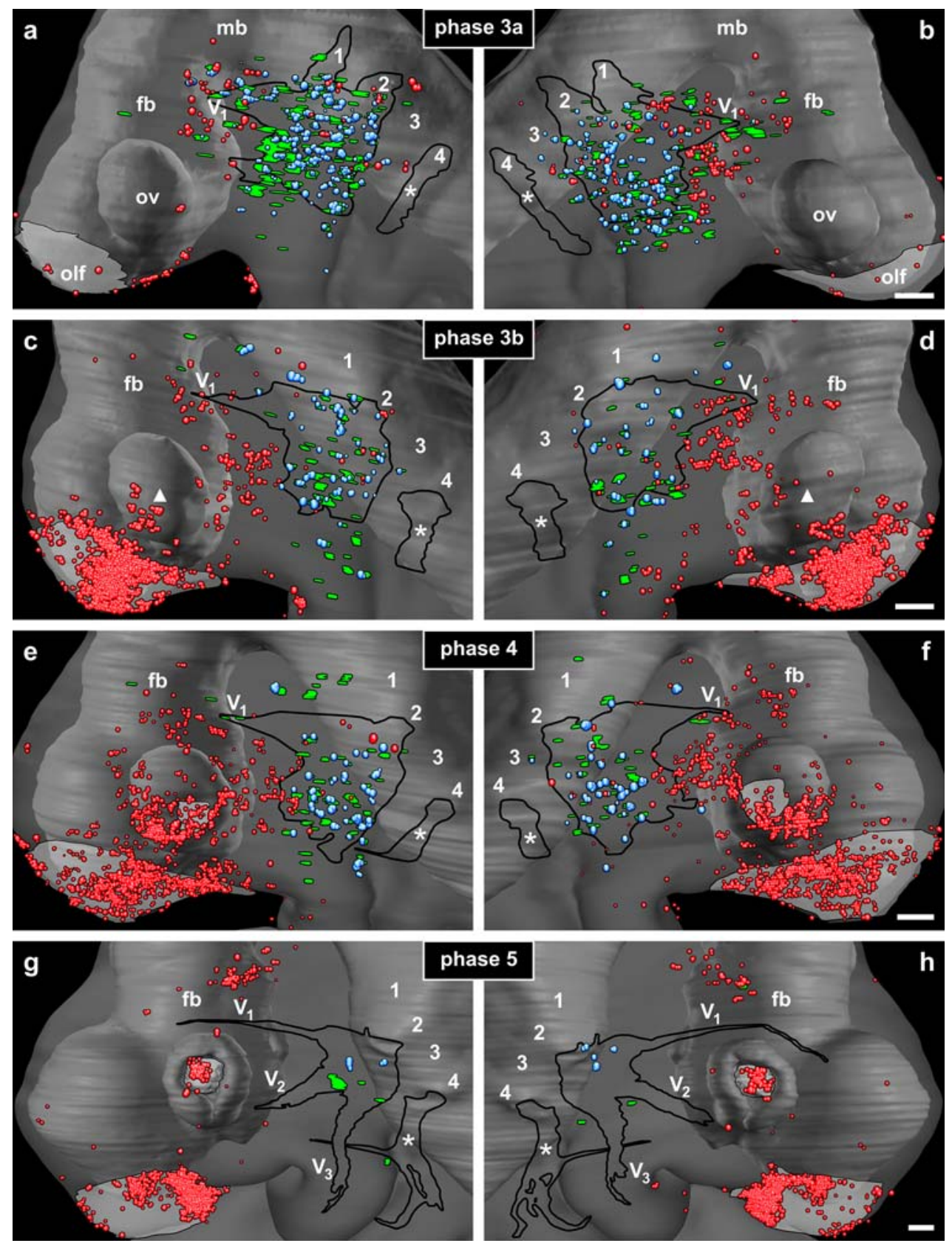

Fig. 6 Apoptosis in the mature and regressing trigeminal placode, 3D reconstructions, Tupaia belangeri, phases 3-5, shown are left (a, c, e, g) and right sides $(\mathbf{b}, \mathbf{d}, \mathbf{f}, \mathbf{h})$ of the embryonic heads. Apoptotic cells (red, 3.25- to 4.5-fold radius) are centered on the placodal field of focal ectodermal thickenings (green) during the peak of trigeminal neuroblast delamination (blue, 2.25- to 4-fold radius) (a, b) and, with lower numbers, in the regressing trigeminal placode $(\mathbf{c}-\mathbf{f})$. Most densely aggregated apoptotic cells constitute a "wedge" which, in phase $3 \mathrm{a}(\mathbf{a}, \mathbf{b})$, extends from the ophthalmic placode to the postulated position of the ventrolateral postoptic placode (Lee et al. 2003). Shortly thereafter (c-f), this wedge "merges" with groups of

to the ophthalmic lobe (Fig. 7b-d, but see Discussion). Upon complete regression of the trigeminal placode (phase 6), subectodermal concentrations of apoptotic bodies were apoptotic cells that are associated with the lens placode (triangle), the latter demonstrating grade 4 thickening (light gray: "at least three rows of epithelial cells") from phase 4 onwards. In phase 5, apoptosis disappears from the confines of the pre-existing placodal field, but persists at the site of lens detachment $(\mathbf{g}, \mathbf{h})$. Note high numbers of apoptotic cells in the olfactory placode (olf, grade 4 thickening shown in light gray) from phase $3 \mathrm{~b}$ onwards $(\mathbf{c}-\mathbf{h})$. 1-4 rhombomeres 1-4, black lines trigeminal ganglion/nerves and facial nerve (asterisks), $f b$ forebrain, gray brain, $m b$ midbrain, ov optic vesicle, transparent gray surface ectoderm, V1, V2, V3 ophthalmic, maxillary, and mandibular nerves, respectively. Scale bars $=100 \mu \mathrm{m}$

almost absent from the former position of the placode (Fig. 7e). Nevertheless, concentrations of apoptotic bodies persisted in the confines of the trigeminal ganglion. 
Table 2 Apoptosis observed during the morphogenesis of the trigeminal placode

\begin{tabular}{lllll}
\hline Phase & $\begin{array}{l}\text { Number of } \\
\text { embryo in } \\
\text { the collection }\end{array}$ & $\begin{array}{l}\text { Early placodal field } \\
\text { (level: cauda } \\
\text { forebrain to } \\
\text { rhombomere 2) }\end{array}$ & $\begin{array}{l}\text { Mature and } \\
\text { regressing } \\
\text { trigeminal } \\
\text { placode }\end{array}$ & $\begin{array}{l}\text { Wedge of apoptotic } \\
\text { cells (level: caudal } \\
\text { forebrain to } \\
\text { midbrain/hindbrain } \\
\text { boundary) }\end{array}$ \\
\hline 2 & $\begin{array}{l}(+),+ \\
\text { Bat 196/A }\end{array}$ & $(+),(+)$ & & \\
Bat 1284/A &,++ & & \\
Bat 1396D/B &,$+(+)$ & & \\
Bat 1396D/C &,++ & &,$+(+)$ \\
Bat 1566/B &,++ & $(+),+$ &,++ \\
Bat 1566/C & &,++++ &,++++ \\
DPZ 870/11A & &,++++ &,++ \\
DPZ 870/12C & &,$+(+)$ &,++++ \\
Bat 198/A & &,++++ & $(+),+$ \\
Bat 198/C & &,$+(+)$ &,++++ \\
Bat 962/C & &,++ &,++ \\
Bat 962/D & &,++ & \\
DPZ 743/4B & & & \\
DPZ 1384/A & & &
\end{tabular}

Different from phase 3 , these apoptotic bodies were distributed throughout the ganglion and even tended to accumulate in its medialmost parts (Fig. 7f).

From at least phase $3 \mathrm{~b}$ onwards, single or groups of large neuroblasts of presumed placodal origin were found close to the developing ophthalmic nerve (Fig. 8a). Outgrowth of the oculomotor nerve started in phase 4 (data not shown). From phase 5 onwards, groups of neuroblasts were found in the vicinity of the distal oculomotor nerve, of the ophthalmic nerve, and of the "meeting point" of the two nerves (Fig. 8b-d).

\section{Discussion}

Structural properties of the trigeminal placode

Bartelmez and Evans (1926) reported that, in human embryos, the trigeminal placode ("area V") consists of continuously thickened ectoderm. In contrast, a "diffuse" nodular texture of the trigeminal placode has been observed in the pig (van Campenhout 1936), rabbit (Coërs 1946), cat (Halley 1955) and sheep (Batten 1957). Histologic findings in the laboratory mouse are somewhat in between the two "extremes" of the spectrum (Nichols 1986). On the one hand, ophthalmic and maxillomandibular parts of the trigeminal placode demonstrate a continuously thickened cubic or columnar epithelium, respectively. On the other hand, groups of horizontally stapled ectodermal cells stand out from this continuously thickened epithelium, most pronouncedly in ophthalmic parts of the placode (Nichols 1986). Corresponding "papillary-like" thickenings are additionally found in the otherwise continuously thickened trigeminal placode of the laboratory rat (Adelmann 1925). Taking for granted that placodes are solid patches of ectoderm, Adelmann (1925, p 108) concluded that the ectoderm above the first pharyngeal arch "is so slightly thickened and the slight thickening so diffuse that it is extremely improbable that it constitutes a true placode". In T. belangeri, a welldelimited continuously thickened trigeminal placode was not observed in any of the studied embryos. Instead, during our phases 1-5, a "placodal field" was noted which consists of abundant focal thickenings. Only during the onset of placode formation, this field is "embedded" in continuously thickened cubic ectoderm (phase 1 and, less conspicuous, phase 2). However, these continuously thickened parts of the ectoderm extend from anteriormost parts of the head to at least the first pharyngeal cleft (data not shown). Hence, three-dimensional reconstructions of different "grades" of continuously thickened parts of the surface ectoderm (Washausen et al. 2005) did not help to identify the borders of the trigeminal placode. We conclude that, like in chick embryos (D'Amico-Martel and Noden 1983; Hamburger 1961), a diffuse texture of the trigeminal placode is a characteristic feature of $T$. belangeri (present results) as well as of most other mammals studied (Adelmann 1925; Batten 1957; Coërs 1946; Halley 1955; Nichols 1986; van Campenhout 1936). That, in fact, solid or diffuse "phenotypes" of placodes are not mutually exclusive has already been shown for the epibranchial placodes. In $T$. belangeri, the caudalmost out of three pairs of epibranchial placodes first consists of several focal high-grade thickenings which, in the continued 

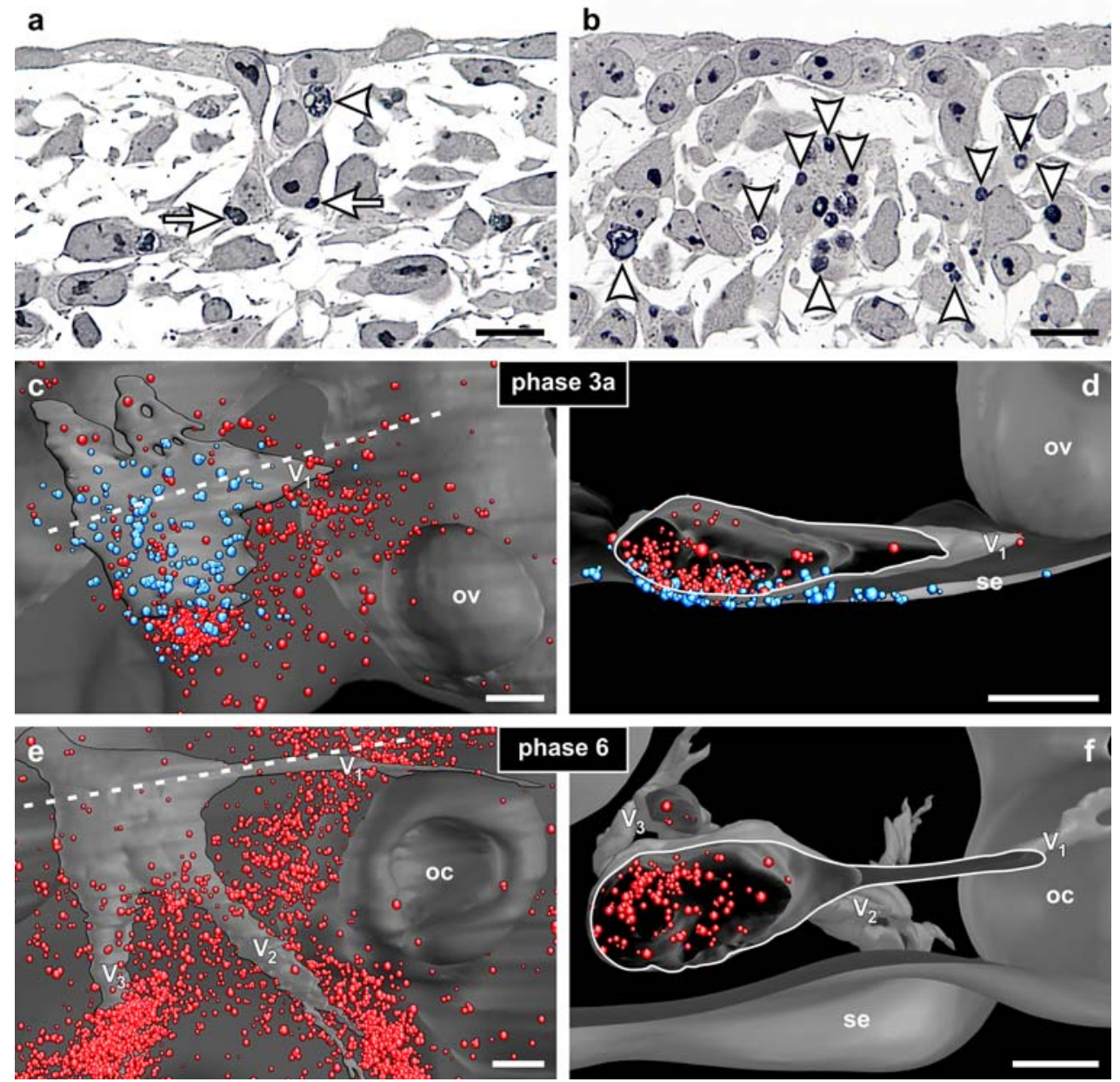

Fig. 7 Apoptosis in the developing trigeminal ganglion, Tupaia belangeri. a and b Hematoxylin-stained semithin sections $(1 \mu \mathrm{m})$. During neuroblast delamination (a phase 4, DPZ 743/1A; b phase 3, DPZ 870/12C), apoptotic bodies are found within the trigeminal placode (arrowhead in a), in delaminating neuroblasts (arrows in a) as well as in the mesenchymal compartment beneath the placode (arrowheads in b). c-f 3D reconstructions (c, e lateral views; $\mathbf{d}, \mathbf{f}$ dorsal views, horizontally sectioned as indicated by white dashed lines in c, e) demonstrate that, during the peak of neuroblast delamination (blue, 1.75- to 2-fold radius), apoptotic cells (red, 2.5- to 4-fold radius) are concentrated in the narrow mesenchymal compartment laterally adjacent to the maxillomandibular, but not ophthalmic

presence of neuroblast delamination, secondarily "unite" into a single solid placode (Washausen et al. 2005).

Position of the trigeminal placode

Using focal DiI and DiO labeling, Xu et al. (2008) have demonstrated that, in chick embryos, ophthalmic parts of the trigeminal placode ultimately reside lateral to the caudal midbrain and rhombomeres 1 and 2, whereas maxillomandibular parts are found lateral to rhombomeres 2 and 3. However, two additional lines of evidence have to be considered. First, Lee et al. (2003) have postulated the b
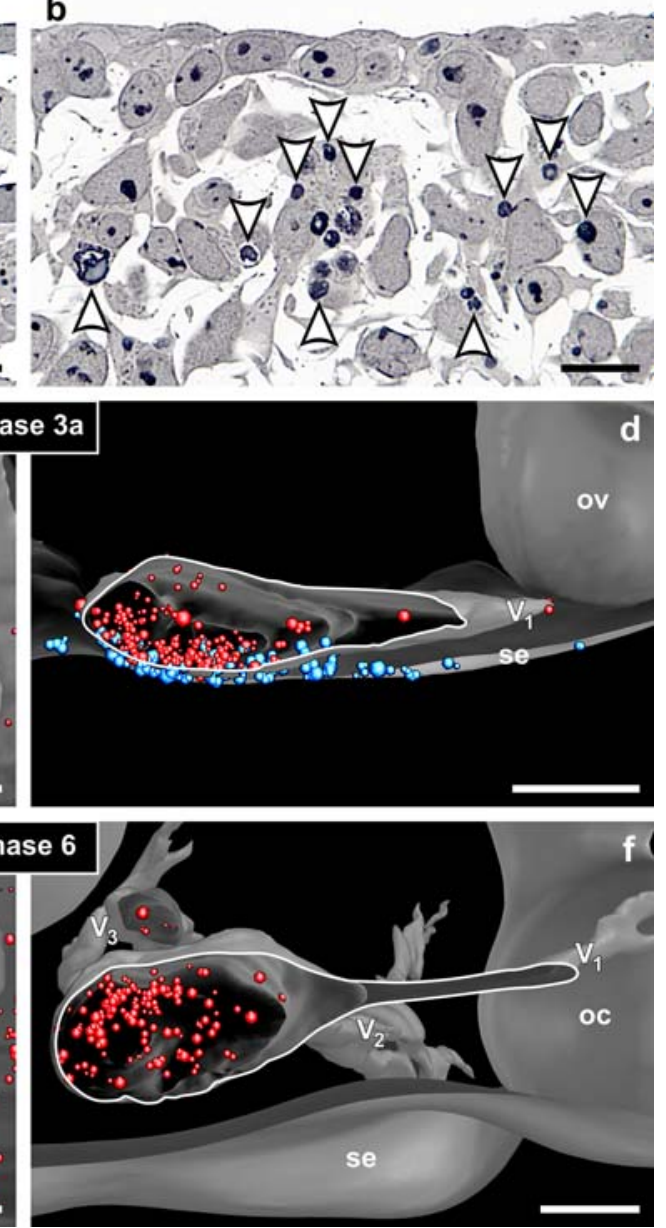

d

ganglionic lobe (c) and, separately reconstructed, in lateralmost parts of the maxillomandibular, but not ophthalmic lobe (d). Following regression of the placode, decreased numbers of apoptotic cells are found in the mesenchyme laterally adjacent to the trigeminal ganglion (e), and apoptotic cells within the ganglion (separately reconstructed) are almost randomly distributed (f). Apoptotic cells (of presumed neural crest origin) in the mesenchyme rostral to the first pharyngeal cleft (c, e) are most densely aggregated along the developing ophthalmic (V1), maxillary (V2), and mandibular nerves (V3). Gray brain and trigeminal ganglion/nerves, oc optic cup, ov optic vesicle, se surface ectoderm, transparent gray surface ectoderm in c, e. Scale bars $=10 \mu \mathrm{m}$ in $\mathbf{a}, \mathbf{b} ; 100 \mu \mathrm{m}$ in $\mathbf{c}-\mathbf{f}$

existence of a "ventrolateral postoptic placode" which "is likely to be a ventral extension of the rostral trigeminal ophthalmic placode". Second, more recent studies have suggested that rostralmost parts of the ophthalmic trigeminal placode reside adjacent to the caudal forebrain and, thus, extend further rostrally than previously thought (McCabe et al. 2009). Having at hands these landmarks, multiparametric reconstructions of embryonic $T$. belangeri were performed to analyze the respective composition of the placodal field during the six developmental phases studied. Our reconstructions included: (1) the entire brain, (2) the streams of neural crest cells delivered by the 


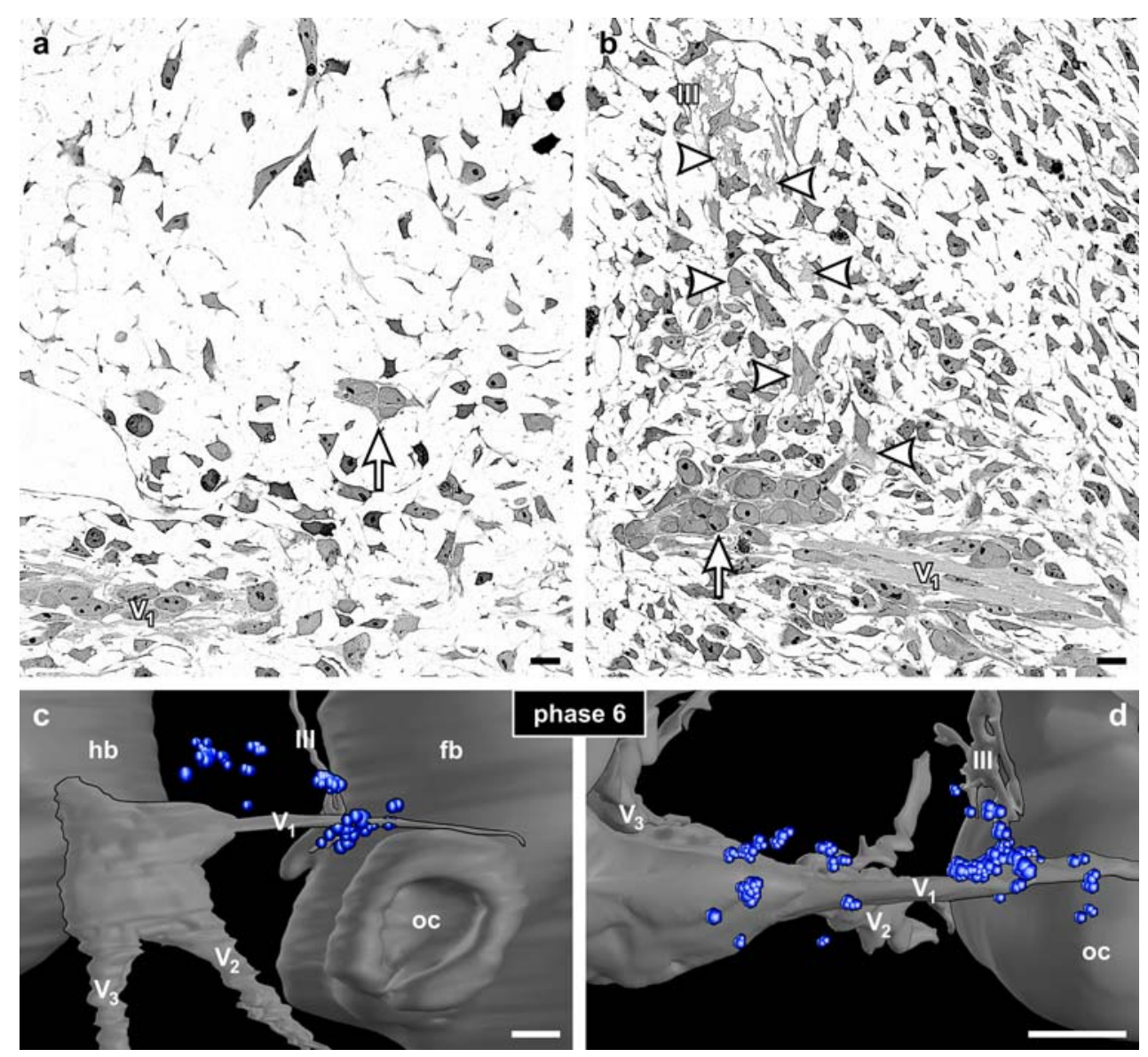

Fig. 8 Placodal contribution to the ciliary ganglion/oculomotor complex, Tupaia belangeri, phases 4 and 6, hematoxylin-stained semithin sections $(1 \mu \mathrm{m})(\mathbf{a}, \mathbf{b}), 3 \mathrm{D}$ reconstructions (c: lateral view; d: dorsal view). a Phase 4 (DPZ 743/1A). Large neuroblasts (arrow) which, possibly, have delaminated from the placodal field of focal ectodermal thickenings (see Figs. 2, 3a, b) are found inward and rostrally ahead of the developing ophthalmic nerve (VI). b-d Phase 6. Single or groups of large neuroblasts (b arrow; $\mathbf{c}, \mathbf{d}$ dark blue, 2.5- to

hindbrain, (3) the trigeminal ganglion, (4) relevant cranial nerves, and (5) all cells caught during the process of emigration from the surface ectoderm rostral to the first pharyngeal cleft. It turned out that the placodal field is subject to positional changes along combined rostrocaudal and dorsoventral gradients throughout the studied time window. It successively holds positions: (1) between the rostral forebrain and rhombomere 1 (phase 1a), (2) between the caudal forebrain and rhombomere 2 (phases $1 \mathrm{~b}, 2 \mathrm{a})$, (3) between the forebrain-midbrain boundary and rhombomere 3 (phases 2b, 3a), (4) between the caudal midbrain and rhombomere 3 (phases $3 \mathrm{~b}, 4$ ) and, upon regression, (5) between the rhombomeres 1 and 3 (phase 5). Taking previous findings in chick embryos as a basis for a comparison (Lee et al. 2003; McCabe et al. 2009; Xu et al. 2008), those parts of the placodal field which, in $T$. belangeri, reside adjacent to the caudal midbrain and
4.25 -fold radius) reside along the ophthalmic nerve, the distal oculomotor nerve (III), at the "meeting point" of the two nerves, and adjacent to fiber bundles (arrowheads in b) which help to establish the ciliary ganglion/oculomotor complex. Gray brain and the developing trigeminal/oculomotor nerves, $f b$ forebrain, $h b$ hindbrain, $o c$ optic cup, V2, V3 maxillary and mandibular nerves, respectively. Scale bars $=10 \mu \mathrm{m}$ in $\mathbf{a}, \mathbf{b} ; 100 \mu \mathrm{m}$ in $\mathbf{c}, \mathbf{d}$

rhombomeres 1-3 match the ultimate position of the trigeminal placode demonstrated by $\mathrm{Xu}$ et al. (2008). Other parts of the placodal field which, in $T$. belangeri, were additionally found lateral to the forebrain and/or lateral to the rostral midbrain appear to confirm the reported rostral extension of the ophthalmic trigeminal placode (McCabe et al. 2009) and, possibly, include the postulated position of the ventrolateral postoptic placode (Lee et al. 2003).

Neuroblast delamination in the trigeminal placode

In $T$. belangeri, delamination of neuroblasts is restricted to the confines of the placodal field but, resembling findings in the ophthalmic trigeminal placode of chick embryos (McCabe et al. 2009), is sparse in positions lateral to the forebrain. Positional changes of the placodal field and of clusters of delaminating neuroblasts take 
place in parallel. These findings as well as the observed order of appearance of the trigeminal ganglion lobes strengthen the view that, in $T$. belangeri, onset (and termination) of neuroblast delamination first occur in ophthalmic parts of the trigeminal placode and, with a delay, in its maxillomandibular parts. In tendency, this sequence of events was also observed in Xenopus laevis (Schlosser and Northcutt 2000; Schlosser and Ahrens 2004), Ambystoma mexicanum (Northcutt and Brändle 1995), Scyliorhinus canicula (O’Neill et al. 2007), chick embryos (D'Amico-Martel and Noden 1983; McCabe et al. 2009) as well as in the sheep, cat, and pig (Batten 1957; Halley 1955; van Campenhout 1936). However, among studied mammals, discrete differences appear to exist regarding trigeminal placode activity. Thus, unlike in $T$. belangeri, termination of neuroblast delamination in maxillomandibular parts of the placode either appears to parallel (cat: Halley 1955) or even to precede that in ophthalmic parts (sheep and pig: Batten 1957; van Campenhout 1936).

Subsections of the trigeminal placode

In X. laevis, solid "profundal" (ophthalmic) and "trigeminal" (maxillomandibular) placodes are contiguous on stage 14. From stage 27 onwards, this complex dissociates into two separate placodes (Schlosser and Northcutt 2000). In chick embryos, subsections of the diffusely structured trigeminal placode have been identified by their differential expression of transcription factors. The paired box transcription factor pax3 is expressed in the ophthalmic, but not in the maxillomandibular placode (Stark et al. 1997; Xu et al. 2008). Conversely, the proneural transcription factor neurogenin 1 is expressed in the maxillomandibular, but not in the ophthalmic placode (Begbie et al. 2002). Our reconstructions in $T$. belangeri consistently reveal contiguous fields of focal ectodermal thickenings but, in no case, separate ophthalmic and maxillomandibular placodes. However, during the onset of massive neuroblast delamination (phase 2), up to four separate clusters of delaminating cells are found, bilaterally symmetrically, in ectodermal positions between the caudal forebrain and rhombomere 2. Taking the developing trigeminal ganglion and nerves as the landmarks, these clusters may represent transiently separated ophthalmic and maxillomandibular trigeminal placodes. Presumed subsections of the trigeminal placode become indistinct during the peak period of delamination (phase 3a, Fig. 3a, b), but indirectly "reappear" due to the precocious regression of ophthalmic parts of the placode (phases 3b-5, Fig. 3c-h). Hence, our findings in $T$. belangeri provide limited evidence for the existence of separate ophthalmic and maxillomandibular placodes.
"Ventrolateral postoptic placode"

Using focal injections of DiI applied to the ectoderm caudal to the optic anlagen, Lee et al. (2003) found evidence for a "ventrolateral postoptic placode" which, in chick embryos, contributes sensory neuroblasts to the ciliary ganglion and its associated structures. According to Lee et al. (2003), the ventrolateral postoptic placode should be contiguous with ophthalmic parts of the trigeminal placode. However, structural equivalents of this novel placode have not been demonstrated so far, and virtually nothing is known about whether this placode exists in mammals. In $T$. belangeri, candidate structural equivalents of a ventrolateral postoptic placode exist during our phases 1-3 and, being part of the placodal field, are contiguous with the trigeminal placode. Nevertheless, a decision on whether rostralmost parts of the ophthalmic trigeminal placode which, in chick embryos as well as in T. belangeri, appear to extend further rostrally than previously thought (McCabe et al. 2009; present results) can be distinguished from a separate ventrolateral postoptic placode awaits experimental evidence. In $T$. belangeri, delamination from the ventrolateral postoptic ectoderm (level: caudal forebrain to rostral midbrain) is sparse in phase 1 , moderate in phase 2, and decreases in phase 3. Separate clusters of delaminating cells are found, bilaterally symmetrically, in phase 2 and, less distinct, in phase 3a. Correspondingly, single or small groups of neuroblasts adjacent and/or rostrally ahead of the developing ophthalmic nerve are first noted in phase $3 \mathrm{~b}$. During phases 4-6, regression of the placodal field is paralleled by the aggregation of large neuroblasts along the ophthalmic nerve, the distal oculomotor nerve, and at the "meeting point" of the two nerves which start to become interconnected. Our findings in $T$. belangeri suggest that placode-derived "pioneer" neurons, like in chick embryos, may promote the elongation of the ophthalmic nerve (McCabe et al. 2009) and may help to establish the ciliary ganglion/oculomotor complex (Lee et al. 2003). Future studies in T. belangeri will address presumed interactions of neural crest cells and placodal cells during the development of the ciliary ganglion and its associated structures.

Apoptosis and proliferation in the trigeminal placode

Encouraged by our previous findings in the epibranchial placodes (Washausen et al. 2005), we presently aimed to clarify whether spatiotemporally regulated interactions of proliferative and apoptotic events also contribute to the morphogenesis of the trigeminal placode. We show that groups of apoptotic cells are selectively present in the confines of the placodal field prior to the onset of massive neuroblast delamination (phase 1), during the peak period 
of delamination (phases 2-3) and, finally, upon regression of the trigeminal placode (phases 4-5). The observed patterns of apoptotic events constitute a rostrocaudal wave of apoptosis which continuously passes through the developing, mature, and regressing trigeminal placode, thereby providing the opportunity to eliminate subpopulations of epidermal precursor cells, placodal precursor cells and/or premigratory placodal neuroblasts. Our hypothesis is corroborated, at least in part, by two recent findings in chick embryos. According to $\mathrm{Xu}$ et al. (2008), ophthalmic and maxillomandibular placode precursors "are initially extensively intermingled with each other, with otic and geniculate (the first epibranchial) precursors, and with epidermal precursors". Provided that mixing of migratory placodal and epidermal precursor cells also takes place in the placodal field found in T. belangeri, apoptosis may assist in correcting for migratory errors. Second, in chick embryos, ophthalmic trigeminal placode cells initiate neurogenesis early and while still in the ectoderm (McCabe et al. 2009). Provided, again, that an early onset of neurogenesis also takes place in the trigeminal placode of $T$. belangeri, apoptosis may additionally eliminate subpopulations of (possibly wrongly specified) premigratory placodal neuroblasts.

In $T$. belangeri, a massive wedge of apoptotic ectodermal cells transiently extends from positions adjacent to the caudal forebrain to rostralmost parts of rhombomere 1 . Further consideration of this wedge is required for at least three reasons. (1) The wedge descends ventrad from the ophthalmic placode, thereby running rostrally ahead of the maxillomandibular placode. Hence, the wedge of apoptotic cells somehow reflects the postulated position of the ventrolateral postoptic placode (Lee et al. 2003). (2) Most probably, apoptosis in the confines of the wedge first eliminates subpopulations of premigratory ophthalmic neuroblasts (phase 3) and, with a delay, promotes the regression of the ophthalmic trigeminal placode (phase 4). On the first glance, massive apoptosis in the ophthalmic placode appears to contrast with comparatively moderate numbers of apoptotic cells found in the maxillomandibular placode (Fig. 6a-f). However, during the peak period of neuroblast delamination (phase 3a), seemingly moderate numbers of apoptotic cells in the maxillomandibular placode occurred in association with high numbers of apoptotic cells found in the mesenchyme underneath the maxillomandibular placode as well as in lateralmost parts of the maxillomandibular ganglionic lobe (Fig. 7c, d). These findings suggest that, in $T$. belangeri, most maxillomandibular cells die after having left the placode, while most ophthalmic cells may die before leaving the placode. It remains to be clarified as to what extent neural crest cells undergo apoptosis in the studied non-placodal compartments, and whether redistribution of apoptotic cells in the phase 6 trigeminal ganglion already reflects target-dependent apoptosis. (3) During our phases $3 \mathrm{~b}$ and 4, apoptotic cells belonging to the pre-existing wedge "merge" with other groups of apoptotic cells being loosely associated with the developing lens placode. This finding suggests that precursor cells of the transforming panplacodal primordium which, for unknown reasons, do not become integrated into the trigeminal or lens placodes, are eliminated. Correspondingly, groups of apoptotic cells were transiently intercalated between the developing otic placode and the first epibranchial placode and, with a delay, between neighboring epibranchial placodes (Washausen et al. 2005).

In $T$. belangeri, morphogenesis of the three paired epibranchial placodes depends on interactions of spatiotemporally regulated waves of proliferative and apoptotic events. Onset of the proliferative wave precedes that of the apoptotic wave by about one out of six developmental phases studied (Washausen et al. 2005). The present work demonstrates that similar interactions also contribute to the morphogenesis of the trigeminal placode. Already in phase $1 \mathrm{~b}$, mitotic cells tend to be concentrated in the placodal field. The peak of proliferation (phase 2) precedes that of apoptosis and neuroblast delamination by about one phase. From phase 3 onwards, proliferation decreases in the trigeminal placode, but increases in the anlagen of the lens and olfactory placodes thereby, again, preceding massive apoptosis in these rostral placodes by about one phase.

Taken together, previous findings in the epibranchial placodes (Washausen et al. 2005) and present findings in the trigeminal placode demonstrate that, in $T$. belangeri, principally identical patterns of proliferative and apoptotic events contribute to the morphogenesis of different neurogenic placodes. Obviously, these contributions are not restricted to the regulation of activities in the mature and regressing placodes. Instead, complex patterns of apoptosis also surround and "separate" the developing placodes. The diffuse texture of the trigeminal placode as well as the extensive positional changes of the underlying field of focal ectodermal thickenings which, possibly, represent groups of migrating precursor cells, may well reflect arrested steps in the transformation of the panplacodal primordium. Hence, transformation of the contiguous panplacodal primordium into individualized placodes may be cooperatively accomplished by translocations of mixed groups of precursor cells (Bhattacharyya et al. 2004; Dutta et al. 2005; Streit 2002; Xu et al. 2008) and by spatiotemporally regulated interactions of apoptotic and proliferative events among placodal precursor cells (Washausen et al. 2005; present results). However, positional changes of the placodal field such as have been observed in $T$. belangeri do not necessarily reflect migratory movements of placodal precursor cells. Instead, they may have alternatively resulted from a combination of regressing 
focal ectodermal thickenings anteriorly and newly forming thickenings posteriorly without involving any translocation of cells.

Acknowledgments We thank Dr. Marek Vanco and Dipl.-Inf. Enrico Kienel, Technische Universität Chemnitz, for help with the three-dimensional reconstructions, and Irmgard Weiss for technical assistance. This work was supported by the Deutsche Forschungsgemeinschaft (KN 525/1-1, KN 525/1-2, BR 1185/4-1, and former Sonderforschungsbereich 89: Cardiology).

Open Access This article is distributed under the terms of the Creative Commons Attribution Noncommercial License which permits any noncommercial use, distribution, and reproduction in any medium, provided the original author(s) and source are credited.

\section{References}

Adelmann HB (1925) The development of the neural folds and cranial ganglia of the rat. J Comp Neurol 39:19-171. doi:10.1002/cne. 900390103

Asher RJ, Bennett N, Lehmann T (2009) The new framework for understanding placental mammal evolution. Bioessays 31:853864. doi:10.1002/bies.200900053

Bailey AP, Bhattacharyya S, Bronner-Fraser M, Streit A (2006) Lens specification is the ground state of all sensory placodes, from which FGF promotes olfactory identity. Dev Cell 11:505-517. doi:10.1016/j.devcel.2006.08.009

Baker CVH, Bronner-Fraser M (2001) Vertebrate cranial placodes. I. Embryonic induction. Dev Biol 232:1-61. doi:10.1006/dbio. 2001.0156

Bartelmez GW, Evans HM (1926) Development of the human embryo during the period of somite formation, including embryos with 2-16 pairs of somites. Contrib Embryol Carnegie Inst 17:1-67

Batten EH (1957) The activity of the trigeminal placode in the sheep embryo. J Anat 91:174-187

Begbie J, Ballivet M, Graham A (2002) Early steps in the production of sensory neurons by the neurogenic placodes. Mol Cell Neurosci 21:502-511. doi:10.1006/mcne.2002.1197

Bhattacharyya S, Bailey AP, Bronner-Fraser M, Streit A (2004) Segregation of lens and olfactory precursors from a common territory: Cell sorting and reciprocity of Dlx5 and Pax6 expression. Dev Biol 271:403-414. doi:10.1016/j.ydbio.2004. 04.010

Boissonnat JD (1988) Shape reconstruction from planar cross sections. Comput Vision Graph Image Proc 44:1-29. doi: 10.1016/S0734-189X(88)80028-8

Brugmann SA, Moody SA (2005) Induction and specification of the vertebrate ectodermal placodes: precursors of the cranial sensory organs. Biol Cell 97:303-319. doi:10.1042/BC20040515

Brunnett G, Vanco M, Haller C, Washausen S, Kuhn H-J, Knabe W (2003) Visualization of cross sectional data for morphogenetic studies. In: Dittrich K, König W, Oberweis A, Rannenberg K, Wahlster W (eds) Proceedings GI workshop "Visualisierung in der Bioinformatik". Lecture notes in informatics, vol 34. Köllen, Bonn, pp 354-359

Coërs C (1946) La formation des nerfs mixtes craniens chez le lapin. Arch Biol (Liège) 57:13-77

D'Amico-Martel A, Noden DM (1983) Contributions of placodal and neural crest cells to avian cranial peripheral ganglia. Am J Anat $166: 445-468$
Dutta S, Dietrich J-E, Aspöck G, Burdine RD, Schier A, Westerfield M, Varga ZM (2005) pitx3 defines an equivalence domain for lens and anterior pituitary placode. Development 132:15791590. doi:10.1242/dev.01723

Goping G, Wood KA, Sei Y, Pollard HB (1999) Detection of fragmented DNA in apoptotic cells embedded in LR white: a combined histochemical (LM) and ultrastructural (EM) study. J Histochem Cytochem 47:561-568

Häcker G (2000) The morphology of apoptosis. Cell Tissue Res 301:5-17. doi:10.1007/s004410000193

Halley G (1955) The placodal relations of the neural crest in the domestic cat. J Anat 89:133-152

Hamburger V (1961) Experimental analysis of the dual origin of the trigeminal ganglion in the chick embryo. J Exp Zool 148: 91-123. doi:10.1002/jez.1401480202

Kienel E, Vanco M, Brunnett G, Kowalski T, Clauß R, Knabe W (2007) A framework for the visualization of cross sectional data in biomedical research. In: Linsen L, Hagen H, Hamann B (eds) Mathematics and visualization. Visualization in medicine and life sciences. Springer, Berlin, pp 77-97

Knabe W, Kuhn H-J (1998) Pattern of cell death during optic cup formation in the tree shrew Tupaia belangeri. J Comp Neurol 401:352-366. doi:10.1002/(SICI)1096-9861(19981123)401:3<352:: AID-CNE4>3.0.CO;2-A

Knabe W, Washausen S, Brunnett G, Kuhn H-J (2002) Use of "reference series" to realign histological serial sections for three-dimensional reconstructions of the positions of cellular events in the developing brain. J Neurosci Methods 121:169180. doi: $10.1016 / \mathrm{S} 0165-0270(02) 00247-9$

Knabe W, Washausen S, Brunnett G, Kuhn H-J (2004) Rhombomerespecific patterns of apoptosis in the tree shrew Tupaia belangeri. Cell Tissue Res 316:1-13. doi:10.1007/s00441-004-0855-0

Knabe W, Washausen S, Happel N, Kuhn H-J (2007) Development of starburst cholinergic amacrine cells in the retina of Tupaia belangeri. J Comp Neurol 502:584-597. doi:10.1002/cne.21324

Knabe W, Washausen S, Happel N, Kuhn H-J (2008) Diversity in mammalian chiasmatic architecture: ipsilateral axons are deflected at glial arches in the prechiasmatic optic nerve of the eutherian Tupaia belangeri. J Comp Neurol 508:437-457. doi: $10.1002 / \mathrm{cne} .21694$

Kuhn H-J, Schwaier A (1973) Implantation, early placentation, and the chronology of embryogenesis in Tupaia belangeri. Anat Embryol 142:315-340. doi:10.1007/BF00519135

Lassiter RNT, Dude CM, Reynolds SB, Winters NI, Baker CVH, Stark MR (2007) Canonical Wnt signaling is required for ophthalmic trigeminal placode cell fate determination and maintenance. Dev Biol 308:392-406. doi:10.1016/j.ydbio.2007.05.032

Lee VM, Sechrist JW, Luetolf S, Bronner-Fraser M (2003) Both neural crest and placode contribute to the ciliary ganglion and oculomotor nerve. Dev Biol 263:176-190. doi:10.1016/j.ydbio. 2003.07.004

Litsiou A, Hanson S, Streit A (2005) A balance of FGF, BMP and WNT signalling positions the future placode territory in the head. Development 132:4051-4062. doi:10.1242/dev.01964

Martin K, Groves AK (2006) Competence of cranial ectoderm to respond to Fgf signaling suggests a two-step model of otic placode induction. Development 133:877-887. doi:10.1242/dev.02267

McCabe KL, Bronner-Fraser M (2008) Essential role for PDGF signaling in ophthalmic trigeminal placode induction. Development 135:1863-1874. doi:10.1242/dev.017954

McCabe KL, Sechrist JW, Bronner-Fraser M (2009) Birth of ophthalmic trigeminal neurons initiates early in the placodal ectoderm. J Comp Neurol 514:161-173. doi:10.1002/cne.22004

McLarren KW, Litsiou A, Streit A (2003) DLX5 positions the neural crest and preplacode region at the border of the neural plate. Dev Biol 259:34-47. doi:10.1016/S0012-1606(03)00177-5 
Nechiporuk A, Linbo T, Poss KD, Raible DW (2007) Specification of epibranchial placodes in zebrafish. Development 134:611-623. doi: 10.1242/dev.02749

Nichols DH (1986) Mesenchyme formation from the trigeminal placodes of the mouse embryo. Am J Anat 176:19-31

Northcutt RG, Brändle K (1995) Development of branchiomeric and lateral line nerves in the axolotl. J Comp Neurol 355:427-454. doi:10.1002/cne.903550309

O'Neill P, McCole RB, Baker CVH (2007) A molecular analysis of neurogenic placode and cranial sensory ganglion development in the shark, Scyliorhinus canicula. Dev Biol 304:156-181. doi: 10.1016/j.ydbio.2006.12.029

Romeis B (1989) Heidenhains Eisenhämatoxylin. In: Böck P (ed) Mikroskopische Technik. Urban-Schwarzenberg, Baltimore, pp 219-220

Sanders EJ, Wride MA (1995) Programmed cell death in development. Int Rev Cytol 163:105-173

Schlosser G (2006) Induction and specification of cranial placodes. Dev Biol 294:303-351. doi:10.1016/j.ydbio.2006.03.009

Schlosser G, Ahrens K (2004) Molecular anatomy of placode development in Xenopus laevis. Dev Biol 271:439-466. doi: 10.1016/j.ydbio.2004.04.013

Schlosser G, Northcutt RG (2000) Development of neurogenic placodes in Xenopus laevis. J Comp Neurol 418:121-146. doi: 10.1002/(SICI)1096-9861(20000306)418:2<121::AID-CNE1> 3.0.CO;2-M

Stark MR, Sechrist J, Bronner-Fraser M, Marcelle C (1997) Neural tube-ectoderm interactions are required for trigeminal placode formation. Development 124:4287-4295
Streit A (2002) Extensive cell movements accompany formation of the otic placode. Dev Biol 249:237-254. doi:10.1006/dbio. 2002.0739

Streit A (2007) The preplacodal region: an ectodermal domain with multipotential progenitors that contribute to sense organs and cranial sensory ganglia. Int $\mathrm{J}$ Dev Biol 51:447-461. doi: 10.1387/ijdb.072327as

Süss M, Washausen S, Kuhn H-J, Knabe W (2002) High resolution scanning and three-dimensional reconstruction of cellular events in large objects during brain development. J Neurosci Methods 113:147-158. doi:10.1016/S0165-0270(01)00486-1

Theiler K (1989) The house mouse: atlas of embryonic development. Springer, Berlin

van Campenhout E (1936) Contribution à l'étude de 1'origine des ganglions des nerfs craniens mixtes chez le porc. Arch Biol (Liège) 47:585-604

Washausen S, Obermayer B, Brunnett G, Kuhn H-J, Knabe W (2005) Apoptosis and proliferation in developing, mature, and regressing epibranchial placodes. Dev Biol 278:86-102. doi:10.1016/ j.ydbio.2004.10.016

Webb JF, Noden DM (1993) Ectodermal placodes: contributions to the development of the vertebrate head. Am Zool 33:434-447. doi:10.1093/icb/33.4.434

$\mathrm{Xu}$ H, Dude CM, Baker CVH (2008) Fine-grained fate maps for the ophthalmic and maxillomandibular trigeminal placodes in the chick embryo. Dev Biol 317:174-186. doi:10.1016/j.ydbio.2008. 02.012 